\title{
Radiation Fibrosis
}

National Cancer Institute

\section{Source}

National Cancer Institute. Radiation Fibrosis. NCI Thesaurus. Code C9436.

The formation of scar tissue in the skin and subcutaneous tissues, lungs, genitourinary tract, gastrointestinal tract, and other organs, caused by radiation therapy. 